\title{
Nouvelles découvertes dans le quartier du Mīdān
}

Identification de quatre monuments mamelouks

New Discoveries in the District of Mìdān: Identification of Four Mamluk

Monuments

$$
\text { اكتشافات جديدة في حي الميدان: التعريف بأربعة مبانٍ أثرية مملوكية }
$$

\section{Bassam Dayoub}

\section{OpenEdition}

\section{Journals}

Édition électronique

URL : http://journals.openedition.org/beo/836

DOI : $10.4000 /$ beo. 836

ISBN : 978-2-35459-347-9

ISSN : 2077-4079

\section{Éditeur}

Presses de l'Institut français du Proche-Orient

\section{Édition imprimée}

Date de publication : 1 décembre 2012

Pagination : 67-90

ISBN : 978-2-35159-379-0

ISSN : 0253-1623

\section{Référence électronique}

Bassam Dayoub, « Nouvelles découvertes dans le quartier du Mīdān », Bulletin d'études orientales [En ligne], Tome LXI | décembre 2012, mis en ligne le 20 mars 2013, consulté le 02 mai 2019. URL : http:// journals.openedition.org/beo/836; DOI : 10.4000/beo.836 


\section{Nouvelles découvertes dans le quartier du Mīdān Identification de quatre monuments mamelouks}

Bassam DAYOUB

Le Mīdān, qui tire son nom du Maydān al-Ḥașā, l'Hippodrome des Cailloux, est le quartier de Damas qui témoigne le mieux du développement des faubourgs de la ville. Si chaque époque y a laissé des traces, c'est cependant à l'époque mamelouke que l'on peut commencer à parler de faubourg et que l'urbanisation du quartier a véritablement commencé avec la construction de plusieurs monuments le long de la rue principale. Plusieurs d'entre eux n'ont jamais été identifiés et ne sont connus que sous des noms tardifs. Il apparaît indispensable d'en retracer l'histoire pour bien comprendre l'évolution urbaine du quartier au cours des siècles. Il convient, avant de proposer une identification pour quatre édifices connus comme le Maqām al-Ḥarmal̄i, la Mosquée d'al-Ǧunayd, la Mosquée Abū l-Ṣafā et la Mosquée de Māzī, d'évoquer l'évolution urbaine de ce faubourg.

\section{L'histoire du quartier du Mīdān et son secteur}

Dans cette brève présentation du développement de ce faubourg à travers les siècles, une place importante doit être donnée aux débuts historiques. Nous ne possédons sur ce secteur de la ville extra muros que peu d'informations antérieures à la conquête arabe de l'an 15/636. Dans leur étude «Le paysage antique en Syrie : l'exemple de Damas ${ }^{1} »$, Marianne Dodinet, Jacques Leblanc, Jean-Pierre Vallat et François Villeneuve ont cherché les vestiges des parcellaires gréco-romains dans la campagne de Damas à travers les photos aériennes et ont identifié les traces de la centuriation romaine implantée dans le secteur occupé actuellement par le quartier. Les vestiges archéologiques mis au jour lors de travaux de

1. Il s'agit du sujet d'une thèse en cours intitulée L'expansion urbaine de Damas extra muros depuis l'époque seldjukide jusqu'à la fin de l'époque mamelouke : l'exemple du quartier du Mīdān que je mène sous la direction du Professeur Alastair Northedge à l'université Paris I Panthéon-Sorbonne. Je tiens à remercier le Professeur Northedge pour ses conseils et son soutien et M. Jean-Michel Mouton et Mme Maryse Bideault qui m'ont aidé à modifier le texte de nombreuses fois. Dodinet et al. 1990, p. 345. Voir fig. 3, 8 et 9. 
voirie sont essentiellement des hypogées qui vont de l'époque hellénistique jusqu'à l'époque byzantine ${ }^{2}$ (voir la carte 1 ).

Les sources arabes fournissent, pour ce secteur, quelques indications sur l'existence de monuments antérieurs à l'arrivée des musulmans, comme par exemple une grande église de l'époque byzantine ${ }^{3}$. Après la conquête arabe, deux facteurs jouent un grand rôle dans les débuts historiques de ce quartier : tout d'abord, la consécration d'un espace situé au sud de la ville à un mușallā pour les prières des deux fêtes ${ }^{4}$; d'autre part, la naissance de petites concentrations urbaines (voir la carte 2), surtout dans le secteur méridional ${ }^{5}$, liées à l'installation, à l'extérieur de la ville, des tribus arabes participant à la conquête de la cité.

Ces villages constituent les premiers noyaux urbains extra muros et ont continué de se développer à l'époque abbasside. Selon Huraysāt, l'extension urbaine atteignait le village d'al-Rāhib ${ }^{6}$ (voir la carte 2), mais elle fut interrompue à l'époque fatimide à la suite de troubles et de conflits militaires entre les habitants et l'armée fatimide. Une nouvelle localité al-Šamāsiyya est alors apparue à l'extrémité sud du secteur ${ }^{7}$ comme lieu de campement de prédilection de l'armée ${ }^{8}$. La majorité des villages ont disparu, la plupart du temps absorbés par une extension massive aux époques suivantes, en particulier comme alRāhib, al-Sifliyyīn (voir la carte 2), qui se trouvaient près de la voie principale du Maydān ; d'autres, comme al-Qațā' 'i ' , ont disparu, mais leurs noms subsistent dans le parcellaire.

Au cours de l'époque seldjoukide, les sources parlent d'un hippodrome qui se trouve au sud de la ville, entre la Mosquée de Fulūs ${ }^{10}$ et la Mosquée du Muṣallā (voir la carte) ${ }^{11}$. Ce maydān, appelé Maydān al-Ḥașā (l'Hippodrome des Cailloux) est un des cinq maydān-s de la ville $^{12}$ (voir la carte 1), et utilisé comme lieu d'entraînement et lieu de campement.

2. Ainsi ceux qui ont été découverts à al-Ziftiyya en 1980, à Bāb al-Muṣallā en 1983 (HamūDA 2010, sur le site de la DGAMS, voir http://www.dgam.gov.sy/?d=227\&id=833, consulté le 10 juin 2011), à al-Muğtahid en 1982 (SALIBY 1982, p. 305-309) et en 2009 (voir http://www.discover-syria.com/news/4637, consulté le 10 juin 2010).

3. IBN ‘AsĀKIR, Tārīh Dimašq, II, p. 274.

4. «Espace ouvert généralement à l'extérieur d'une localité et servant à l'occasion des deux fêtes à toute la communauté ». Voir E.I. ${ }^{2}$, VII, p. 659.

5. Les noms des ces derniers dans le secteur sud sont Ālyah et 'Ūwayliyya, al-Rāhib al-Sifliyyīn, Bağ Ḥawrān, alQațī'a et al-Qațā'i' (voir la carte 2), voir IBN 'AsĀKIR, Tārīh, II, p. 368.

6. HUURAYSĀT 1992, p. 408.

7. IBN 'AsĀKIR, Tārīh, II, p. 368.

8. IBN AL-QALĀNISĪ , D̃ayl, p. 4, 6, 15, 16, 52, 57.

9. Voir MunAĞĞID 1949, p. 102-103.

10. Cette mosquée devint par la suite la Zāwiya al-Rifā'iyya; il ne reste de l'ancien monument qu'un mihrāb en stuc. IBN 'AsāKIR, Tārīhn, II, p. 321 ; IBN ŠAdDĀD, A'lāq, p. 155 ; AL-Nu'AYMī, Dāris, II, p. 361 ; SAUVAGET 1932, p. 60, nº31. Il convient de signaler ici que nous utilisons le supplément à l'inventaire des mosquées de Damas datant de 1942 ajouté par Ṭalas lui-même à l'édition de l'ouvrage d'Ibn 'Abd al-Hādī, le Timiār al-maqāṣid. ȚALAs 1975, p. 207, n²07 ;

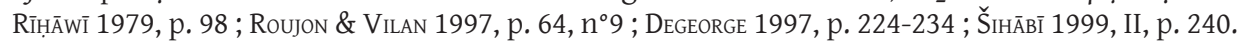

11. Nous avons identifié ce lieu car Ibn 'Asākir est très précis quand il localise la Mosquée de Fulūs au sud de ce maydān. IBN 'AsĀKIR, Tārīh, II, p. 321. Pour les autres propositions d'emplacement, voir MARINo 1997, p. 64-69.

12. Sur les autres maydān-s, voir DAYoub 2010, p. 132. 
Au cours des époques seldjoukide et ayyoubide, la ville a repris son expansion suivant un axe sud, le long de la voie conduisant vers la Mecque comme l'indique la liste donnée par Ibn 'Asākir des nombreux oratoires ponctuant cette zone ${ }^{13}$.

Plusieurs événements sont considérés commeun signe del'importance del'urbanisation de ce secteur, en particulier dans sa partie nord. D'une part, la construction d'une mosquée sur l'emplacement d'al-Mușallā en 607/1211-615/1218 ${ }^{14}$, et l'établissement de la prière du vendredi, et d'autre part, la muraille construite au sud de la Mosquée de Fulūs en 592/1195, afin de protéger la ville lors des conflits entre les émirs ayyoubides, donnent une idée de la densité des habitations qui pousse à son intégration dans le système défensif de la ville ${ }^{15}$. En outre, plusieurs gouverneurs et émirs, ainsi Tuğtakinn ${ }^{16}$, manifestèrent leur volonté d'être enterrés au bord de la «voie sacrée ».

À l'époque mamelouke, on ne parvient pas, au travers des textes historiques, à bien distinguer le quartier de l'hippodrome. Tandis que la partie nord du quartier (al-Musallā, Maydān al-Hașā) s'est développée au fur et à mesure des périodes précédentes, la partie sud a connu, grâce à deux facteurs, un fort essor d'urbanisation lié à l'émergence de plusieurs petites concentrations urbaines, tel que le village d'al-Qubaybāt (les «Petites Coupoles ») ${ }^{17}$ et celui de Maḥla Ğisr al-Fiğl ${ }^{18}$ (le « Pont des Radis »).

Ces deux facteurs sont: la construction de nouvelles grandes mosquées telles que celle de Karīm al-Dīn ${ }^{19}$ dans le village d'al-Qubaybāt ou celle de Manğak ${ }^{20}$ à Maḥla Ǧisr al-Fiğl ; la réalisation de projets hydrauliques ambitieux comme le canal de Karīm al-Dīn, appelé al-Karīmī, qui vit, au cours de la première décade du mois de ša‘bān 720/septembre $1320^{21}$, l'eau s'écouler jusqu'au bassin situé à l'ouest de la mosquée.

13. Sur ces oratoires, voir IBN 'AsĀKIR, Tārīh II, p. 320-321.

14. Al-Nu'́aYmī, Dāris, II, p. 419 ; ABū ŠĀMĀ, Dayl, p. 76.

15. IBN WĀṣIL, Mufarriğ, III, p. 60.

16. Tuğtakīn est mort en 522/1128 et est enseveli au sud d'al-Muṣallā sous les coupoles qui prirent son nom. Voir IBN 'AsĀKIR, Tārīhn, XXV, p. 3.

17. Petit village au sud de la ville qui se trouve actuellement dans le secteur d'al-Mīdān Fūqānī. Marino 1997, p. 117-118; ك̌IHĀBĪ 1999, II, p. 116.

18. C'est une partie du quartier du Maydān al-Ḥașā qui est mentionné antérieurement à la construction de la Mosquée de Manğak en 791/1389-1390. IBN ȘAȘRĀ, Durra, II, p. 33-34-35 ; AL-Nú'AYMĪ, Dāris, II, p. 444 ; Özkan 2005, p. 115, $\mathrm{n}^{\circ} 29$, p. $118, \mathrm{n}^{\circ} 33$.

19. Mosquée mamelouke fondée par le cadi Karīm al-Dīn en 718/1318, appelée aujourd'hui « al-Daqqāq », du nom d'une famille du quartier, voir al-Nu'Aymī, Dāris, II p. 416; AL-'IlmaWī, Muhtașar, p. 225 ; Wulzinger \& Watzinger 1924, p. 102, D.17.2 ; Țalas 1975, p. 217, nº106 ; 'Ulabī 1989, p. 326-327 ; Meinecke 1992, II, p. 122-123 ; Atassi \& Langhade, p. 61 ; Roujon \& Vilan, 1997, p. 67, 70, n²0 ; Marino 1997, p. 72 ; ŠiHāBī 1999, I, p. 121.

20. Mosquée mamelouke fondée en 810/1407-1408. Après plusieurs restaurations, il ne subsiste que quelques assises de la façade ouest portant les deux décrets mamelouks, et le minaret. AL-Nu' AYMī, Dāris, II, p. 444 ; AL-'ILMAWĪ, Muhtașar, p. 235; Wulzinger \& Watzinger 1924, p. 100, D.13.4; SAUVAGET, 1932, p. 71-72, nº50 ; ṬAlas 1975, p. 255, n²281; 'Ulabī 1989, p. 365-357.

21. Un canal fut dérivé de Nahr al-Darānī qui se trouve à l'ouest de la ville. IBN KAṬīr, Bidāya, XVIII, p. 203 ; AL-BIRZĀLĪ, Muqtafì, IV, p. 453-454. 
Différents types des monuments à fonction religieuse (mausolées, mosquées), sociale (des hammams) ou économique (des ḩān-s) sont fondés en bordure de la rue principale (voir la liste en annexe) et dans le quartier, à cette époque, puis à l'époque ottomane où le quartier poursuit son développement urbain jusqu'à ce qu'il constitue, au xix siècle, l'ensemble urbain que nous connaissons aujourd'hui.

Après avoir retracé l'histoire du développement urbain du Mīdān des débuts jusqu'à l'époque ottomane, notre but est d'apporter ici divers arguments et preuves qui permettent de rétablir l'identité et la fonction originelles de quatre édifices de l'époque mamelouke.

\section{Maqām al-Øarmalī (Mausolée al-Qurāğiyya)}

Le mausolée se trouve en retrait à l'est de l'alignement de la rue principale ${ }^{22}$, au sud de la Mosquée de Fulūs (B.2.5), au sud-ouest de la Turba al-Zūwayzāniyya ${ }^{23}$ (B.2.4) et à l'est du Maqām Sīdī Șuhayb ${ }^{24}$,

Le nom actuel du monument, Maqām al-Ḥarmalī, est lié à celui du šayh̆ enseveli à l'intérieur (B.2.2). Ce personnage, connu ordinairement comme Muhammad Harmala ou Harmalī ${ }^{25}$, est cependant ignoré des sources. La seule tentative d'identification de cet édifice a été faite par Yves Roujon et Luc Vilan dans leur ouvrage Le Midan, actualité d'un faubourg de Damas ${ }^{26}$ qui proposent une attribution, toutefois non argumentée, à Alțunbugiā al-Ǧūbānī ${ }^{27}$.

La chronique d'Ibn Qāḍ̄ Šuhba ${ }^{28}$ montre cependant que cette attribution ne peut être retenue. Selon l'auteur, le mausolée de l'émir Alțunbugāa se trouvait à l'ouest d'al-Muṣallā alors que l'édifice appelé Maqām al-Ḥarmalī ${ }^{29}$ est situé au sud dans le même alignement qu'al-Muṣallā. Nous suggérons un autre emplacement pour cet édifice : le mausolée d'Alțunbug̣ā al-Ǧūbānī devait correspondre à la Mosquée Ǧūbān ${ }^{30}$, disparue au cours de la seconde moitié $\mathrm{du} \mathrm{xx}^{\mathrm{e}}$ siècle mais qu'il est possible, à l'appui de plusieurs éléments, de

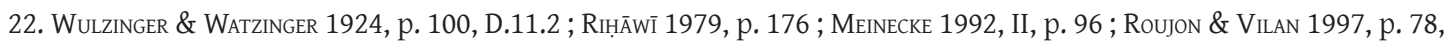
$\mathrm{n}^{\circ} 11$.

23. Mausolée ayyoubide fondé par Ǧamāl al-Dawla Ibn Zūyazān, mort en 628/1230-1231 (B.2.4) ; AL-Nu'AYMī, Dāris, II, p. 247-248 ; Ibn ṬūlūN, Qalä’id, I, p. 175 ; Roujon \& Vilan 1997, p. 78, nº 10.

24. Mosquée qui se trouve à l'ouest de la rue principale et qui abrite le mausolée de Șuhayb, compagnon du prophète Muhammad, ensemble restauré à l'époque ayyoubide en 606/1209-1210. ṬALAs 1975, p. 230, n¹58 ; RiH̄īWĪ 1979, p. 169 ; Roujon \& VILAN 1997, p. 64, nº10.
}

25. Rı̣̂̄Āī 1979, p. 169.

26. Voir pour cette attribution, Roujon \& VILAN 1997, p. 78, n¹1.

27. Gouverneur de Karak, en 787/1385-1386 puis gouverneur de Damas de șafar 789/février- mars 1387 jusqu'à šawwāl 790/octobre-novembre 1388. Après sa sortie de prison, il redevint gouverneur de Damas pour quelques mois, de rabīi I à rağab 792/février 1389 à juillet 1390. IBN QĀḌi ŠUHBA, Tārīh, III, p. 354-355 ; IBN TŪLūN, I'lām, p. 55.

28. IBN QĀDī ŠUHBA, Tārīh, III, p. 355.

29. Voir Roujon \& Vilan 1997, p. 78, nº11.

30. Dans les années 1930, il ne restait de ce monument que « la façade ornée d'incrustations en pierre noire et d'un blason ». Voir Sauvaget 1932, p. 72, n52; Wulzinger \& Watzinger 1924, p. 100, D.10.2 ; ȚAlas 1975, p. 207, n67 ; ŠIHĀBī 1999,II, p. 240. 
localiser à l'ouest d'al-Muṣallā (B.1.1). En effet, le nom de la Mosquée Ǧūbān semble être tiré de la nisba d'Alțunbugà̄ al-Ǧūbānī, le nom de l'ancien maître de l'émir.

En ce qui concerne le Maqām al-Harmalī, nous proposons de l'identifier au Mausolée al-Qurāğiyya. Les chroniques s'accordent sur les indications topographiques relatives au mausolée et indiquent qu'il est situé dans le Maydān al-Hașā près d'une rivière (nahr) ${ }^{31}$. AlBirzālī, plus précis, livre l'information suivante : " près du Mausolée de Șuhayb » ${ }^{32}$. Nous possédons donc trois repères topographiques très importants relatifs à sa localisation.

Cet emplacement correspond très précisément à celui du Maqām al-Ḥarmalī qui était situé à proximité du Mausolée de Șuhayb dans le quartier du Maydān al-Hașā et se trouvait, auparavant, près d'une rivière qui passait de ce côté de la voie. Cette rivière, appelée Nahr al-'Anbāt ou Nahr Qulayț, servait à drainer les eaux usées de la ville ${ }^{33}$ et son tracé, qui figure encore sur une carte établie en 1942, a pu être restitué ${ }^{34}$ (voir la carte 3).

Le fondateur de cette mosquée fut Zayn al-Dīn Qarāğā al-'Alī al-Șāliḥī, tout d'abord gouverneur (wālī) de Izra' ${ }^{35}$, puis ustādār (surintendant) du gouverneur de Damas ${ }^{36}$, mort le 11 muharram 703/1 ${ }^{\text {er }}$ septembre $1303^{37}$.

Il ne reste du monument que les vestiges de la façade et la chambre funéraire du šayh al-Ḥarmalī ${ }^{38}$ (fig. 1, 2, 3). L'entrée de la façade principale se caractérise par un grand arc brisé à l'intrados et extrados godronnés encadrant une porte rectangulaire aux piédroits jouant sur la bichromie des assises alternativement en calcaire rose et en basalte noir. Le linteau monolithe de la porte est surmonté d'un bandeau de lambrequins et d'un oculus aux claveaux noirs et blancs. Chaque côté de la façade est percé de deux fenêtres, celle de la salle funéraire a été transformée en porte.

Cet édifice présente toutes les caractéristiques des monuments mamelouks de Damas : utilisation de l'ablaq ${ }^{39}$ en façade, bandeau de lambrequins et oculus au-dessus de la porte. On peut le rapprocher d'autres monuments de la ville comme la porte à arc godronné de la partie gauche de la Madrasa al- $\bar{A}$ diliyya al-ṣuggrā ${ }^{40}$ reconstruite sous les Mamelouks

31. Al-Nu'AYmī, Dāris, II, p. 271 ; AL-'Ilmawī, Muhtașar, p. 204 ; AL-'AYnī', 'Iqd, IV, p. 339 ; IBn Kațīr, Bidāya, XVIII, p. 37. Sur ce nahr, voir la note $\mathrm{n}^{\circ} 3$.

32. AL-BIRzĀLī, Muqtafï, III, p. 234.

33. Voir AL-SuBKī, Fatāwāt, I, p. 461.

34. Damas : 1 /10 000, «dressé, dessiné et publié par le service géographique des F.F.L.L. d'après réduction des plans cadastraux, mai 1942 ». Cette carte nous a été fournie par l'Atelier du Vieux Damas. Nous remercions ici Mme Sarab Atassi et M. Issam Hağğār.

35. Ville située au sud de Damas, dans la région du Hauran.

36. Le gouverneur était alors Āqūš al-Afram. Voir IBN ṬūLūN, I'lām, p. 37.

37. AL-BIRZ̄̄ì̄, Muqtafï, III, p. 234.

38. Cette chambre était inaccessible lors de nos prospections dans le quartier au cours des étés 2007, 2008 et 2009.

39. L'utilisation de la bichromie des assises de la façade alternativement en deux couleurs (noir et blanc par exemple).

40. Madrasa ayyoubide construite en 686/1287. Al-Nu'AYmī, Dāris, I, p. 368 ; AL-ILmaWī, Muhtașar, p. 58 ; RiHāīī 1979, p. 128 ; 'ULĀBī 1989, p. 139 ; ŠIHĀBī 1999, II, p. 195 ; MEINECKE 1992, II, p. 64, 98. 
bahrides ${ }^{41}$ (fig. 4). Ces données architecturales permettent de situer la fondation de ce monument à l'époque mamelouke, et plus précisément à la période bahride, ce qui conforte notre proposition d'identification de son fondateur qui vivait à ce moment-là.

\section{La Mosquée d'al-Ǧunayd al-'Askarī}

Cet édifice, situé au sud de la Mosquée al-Rifāīi (B.3.3) ${ }^{42}$, dans l'alignement est de la rue principale ${ }^{43}$ (B.3.4), est attribué au célèbre soufi bagdadien al-Ǧunayd ${ }^{44}$ (mort en 217/832833) qui, en réalité, n'est jamais venu à Damas.

En fait, l'édifice a conservé, au-dessus du mihrāb, un acte de waqf auquel personne n'avait jusque-ici prêté attention, qui livre le nom du fondateur, Haydar Ibn al-'Askarī. Nous pouvons légitimement penser que la nisba accolée encore aujourd'hui au nom de la Mosquée Ǧunayd al-'Askarī vient du nom du fondateur.

Ce personnage, dont le nom complet est Ḥaydar b. Yūnus b. al-'Imād Ibn al-'Askarī, fut amìr țablhānāh et wālì l-barr ${ }^{45}$ à Damas en 776/1374-1375. Par la suite, gouverneur de Sinğāar ${ }^{46}$ en 777/1374-1375, il fut emprisonné en 792/1389-1390 ${ }^{47}$, avant de mourir à Damas en šawwāl 801/14 juin-13 juillet $1399^{48}$.

Il a également laissé un autre acte de waqf, rédigé sur papier, où il est fait mention de deux de ses fondations à Damas ${ }^{49}$ : une zāwiya, située au nord de la Turba al-Ğakamiyya ${ }^{50}$, actuellement la Zāwiya al-Sa diyya al-Ǧibāwiyya (D.6.1) ${ }^{51}$, ainsi qu'une mosquée au Maydān al-Ḥașā. Ce second bâtiment semble correspondre à notre édifice. Il est possible que la Mosquée d'Ibn Haydar, mentionnée dans l'acte de waqf figurant dans l'inscription située audessus de mihrāb, ait été transformée dans les années suivantes en mosquée funéraire. En

41. MEINECKe 1992, II, p. 64 ; 98.

42. La mosquée actuelle est ottomane, mais son origine est mamelouke comme l'indique l'inscription située audessus du miḥrāb de la Mosquée d'al-Ǧunayd ; elle fut restaurée en 1928-1931. Ṭalas 1975, p. 218, n¹13 ; Roujon \& VILAN 1997, p. 67, n²13.

43. Țalas 1975, p. 209, n65 ; Meinecke 1992, 2, p. 266 ; Roujon \& Vilan 1997, p. 65, nº14.

44. Voir IBn HुaLliKĀN, Wafayāt, I, p. 373-375.

45. Cette fonction militaire n'est pas mentionnée par al-Qalqašandī mais on la trouve chez al-Ǧazarī : il s'agit du chef de la police dans les régions aux alentours de la ville. AL-QALQAŠANDī, Șubh, IV, p. 187 ; AL-ǦAZARī, Hawādiț. Cet auteur débute chaque année en donnant la liste des autorités de chaque province (hukām al-Bilād).

46. Ville au nord de l'Irak, près de Mossoul. Voir YĀQūT, Mu'ğam, III, p. 262-263.

47. IBN QĀDī ŠUHBA, Tārīhn, III, p. 337.

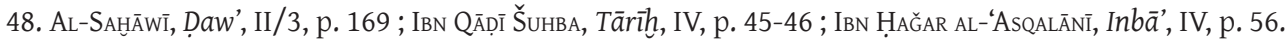

49. ÖZKAN 2005 , p. $186, n^{\circ} 218$.

50. Iвn TūLūn, Mufākahāt, II, p. 71 ; IBN ṬAwQ, Ta`lìq, II, p. 771.

51. Mausolée mamelouk transformé en zāwiya pour la confrérie soufie des Sa'diyya en 914/1508-1509. Voir ALNu'AYMī, Dāris, II, p. 221-222 ; Wulzinger et Watzinger 1924, p. 101, C.16.3 ; SAUVAGET 1932, p. 81, nº72 ; ṬALAS, 1975, p. 253, n² 27 ; 'Ulabī 1989, p. 410-420 ; Atassi \& Langhade 1994, p. 50, nº59 ; Roujon \& Vilan 1997, p. 78, nº 16 ; ŠiHĀBī 1999, 1, p. 336 ; MARINo 1997, p. 78-79. 
effet, Ibn Ṭawq parle d'une Turba al-Ḥaydariyya ${ }^{52}$ située dans le même secteur du Mīdān. La tombe conservée dans la mosquée actuelle, mais dissimulée derrière un faux mur depuis les travaux de reconstruction des années 1930, pourrait ainsi être celle du fondateur.

Dans la mosquée actuelle, reconstruite entre 1932 et $1935^{53}$ (fig. 5-6), la tombe et l'inscription qui se trouve au-dessus de mihrāb sont les seuls vestiges médiévaux. Des quatre inscriptions de la mosquée, seule la plus ancienne, l'acte de waqf, fournit des renseignements permettant une identification.

Mayer n'ayant publié, en 1933, que les trois premières lignes du texte original, et Țalas seulement la première ligne ${ }^{54}$, est ici proposée la première édition intégrale de cette inscription de sept lignes entre listels, en écriture nashī mamelouk avec de grands caractères, des points et des signes diacritiques.

Une photographie de l'inscription dans son état d'origine, publiée par Mayer ${ }^{55}$, confirme que l'opération de recomposition se situe après 1933, date de publication de son livre. Cette opération, survenue à une date indéterminée, a replacé les blocs dans un état aléatoire qui rend confuse la lecture des troisième et quatrième lignes. Un blason en fleur de lys ${ }^{56}$ se trouve placé au milieu de la quatrième ligne sur cette photographie (fig. 8). Notons ici que l'inscription, bûchée sur les quatrième et cinquième lignes, a été regravée à une date inconnue afin d'ajouter de nouveaux biens immobiliers venant compléter le waqf.

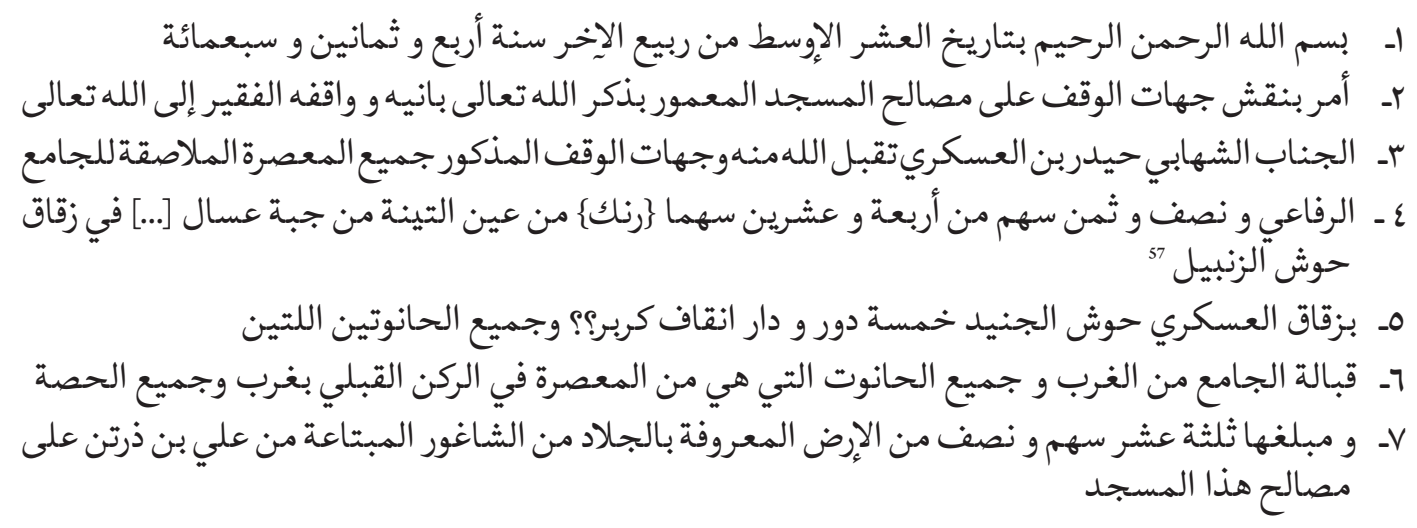

52. IBn ȚAwQ, Ta'līq, II, p. 607.

53. Ces deux dates figurent sur deux inscriptions : la première, située au-dessus de la porte, donne la date de rabīi I de l'année 1352/juin-juillet 1933 ; la seconde, placée au-dessus du mihrāb, livre l'année 1354/1935.

54. ȚALAS 1975, p. 206.

55. MAYER 1999, pl. XIX, fig. 2.

56. Sur ce blason, voir MAYER 1999, p. 22-24, pl. V.

57. Selon Mayer, ce toponyme se rencontrait dans le voisinage de la mosquée. Voir MAYER 1999, p. 118. 


\section{Traduction}

1- Basmala, à la date de la deuxième décade du mois de rabīit II de l'année 784/30 juin-9 juillet 1382,

2- A ordonné de graver l'acte de waqf en faveur de cet oratoire, élevé à la gloire de Dieu, l'avide de Dieu, Très-Haut

3- sa grandeur Šihāb al-Dīn Ḥaydar Ibn al-'Askarī que Dieu accepte cela, ce waqf est constitué de la totalité du pressoir qui se trouve à côté de la mosquée

4- al-Rifā‘̄ d'une demi-partie ${ }^{58}$ et un huitième de partie des vingt-quatre parties\} \{blason en fleur de lys\} \{de "Ayn al-Tīna ${ }^{59}$ de Ğubbat 'Assāl ${ }^{60}$ (...) dans la Zuqāq Ḥawš ${ }^{61}$ al-Zanbīl ${ }^{62}$

5- Zuqāq al-'Askarī ${ }^{63}$, cinq maisons dans Ḥawš Ğunayd et une maison Anqāf Kizbar ${ }^{64}$ de la totalité des deux boutiques

6- qui se situent devant la mosquée à l'ouest et de la boutique qui se trouve au sud-ouest du pressoir, de la totalité de la parcelle

7- dont la valeur est de treize parties et demie de la totalité des vingt-quatre parties de la parcelle de terre dite al-Ǧalād ${ }^{65}$ dans al-šāgūr ${ }^{66}$ qui a été achetée à 'Alī b. Dartin ${ }^{67}$ en faveur de cette mosquée.

Selon nous, l'intérêt premier de ce texte est de mentionner le pressoir, ce qui vient nous éclairer sur des activités développées dans ce secteur autres que les activités commerciales, parce qu'en dehors des terres d'al-Ǧalād et de 'Ayn al-Tīna, tous les biens affectés au waqf sont situés au Mīdān. Par cette fondation Haydar Ibn al-'Askarī s'implante territorialement.

\section{La Mosquée Abū al-Șafā}

Elle se trouve à l'est de la rue principale ${ }^{68}$, au nord du périphérique sud (al-muhallaq al-ğanūbì) de la ville (C.4.2).

Son fondateur n'avait pas été identifié jusqu'ici. Il est toutefois possible de faire un rapprochement avec la zāwiya fondée par le šayh Abū l-Ṣafā au Maydān al-Ḥașā, mentionnée

58. Sur le mot sahm, voir SaUvaget \& MANTRAn 1951, p. 3, n. 3.

59. Petit village situé dans la région d'al-Qalamūn, au nord de Damas (Dussaud 1927, p. 278).

60. Petit village de la région d'al-Qalamūn, au nord de Damas. Cependant, le même nom a été donné, à l'époque mamelouke, à une région située entre Damas et Baalbek. Voir Ȳ̄eūT, Mu'ğam, II, p. 108 ; Dussaud 1927, p. 279.

61. Sur cet habitat, voir PAscual 1983, p. 48-49, n. 1 ; MARINo 1997, p. 253-254.

62. Selon Mayer, ce toponyme se trouvait dans le voisinage de la mosquée. Voir MAYER 1999, p. 118.

63. Il se trouve à l'ouest de la rue principale. Selon Marino, le monument donne son nom à cette ruelle. Voir Marino 1997, p. 111, 358, carte 16.5.a.

64. La lecture n'est pas certaine.

65. Non identifié.

66. Ce nom désigne le faubourg qui se situe à l'extérieur de la porte sud de la ville, Bāb al-Ṣagīir. Cependant, à partir de l'époque ottomane, on trouve deux quartiers portant ce nom, à l'intérieur et à l'extérieur de cette porte. Voir ŠIHĀBİ 1999, I, p. 219.

67. Une autre possibilité de lecture est ذرتر ذرنز.

68. Roujon \& Vilan 1997, p. 65, nº16. 
par le chroniqueur al-Sahāwīī ${ }^{69}$, près de la Mosquée de Manğak (C.4.1). Cet emplacement est en effet tout à fait compatible avec celui de la Mosquée actuelle d'Abū l-Ṣafā. À une époque indéterminée, et selon un processus assez courant à Damas ${ }^{70}$, la zāwiya serait ainsi devenue une mosquée.

Le šayh A bū l-Ṣafā Ibrāhīm b. 'Alīb. Ibrāhīm b. Yūsuf b. 'Abd al-Raḥīm b. 'Alī al-Ḥusaynī ${ }^{71}$ al-'Irāqī al-Maqdisī, né en Irak en 810/1407-1408, habita durant les dernières années de sa vie dans le Maydān al-Ḥasāa et mourut dans sa zāwiya. Il y fut enterré le 6 ğumādā I $887 / 1^{\text {er }}$ juillet $1482^{72}$.

Dans sa forme et son aspect actuels, la mosquée date du début du xx siècle (fig. 9-10) et a été restaurée en 1991 et en 2006. Cependant, selon les habitants du quartier, il y avait jadis à l'intérieur deux tombes ${ }^{73}$, et il est probable que l'une d'entre elles était celle du fondateur.

\section{La Mosquée de Māzī}

Elle est située au sud de la Mosquée d'al-Karīmī (D.7.3), dans le même alignement ${ }^{74}$, à l'extrémité sud du quartier (E.8.1).

L'identification de ce monument est rendue possible grâce à un acte de waqf ${ }^{75}$ daté de l'année 858/1454-1455, conservé à Istanbul, mentionnant un amīr Māzī qui constitua un waqf en faveur de son mausolée situé « au quartier de la Mosquée de Karīm al-Dīn au début d'al-Qubaybāt ».

Deux éléments principaux viennent étayer notre identification. Ce monument est situé précisément dans la zone où l'acte de waqf place le mausolée et il convient d'ajouter que c'est aujourd'hui le seul édifice ancien encore bien conservé dans ce secteur. Quant au fondateur mentionné dans l'acte de waqf sous le nom d'amìr Māzī b. 'Abd Allāh al-Ibrāhīmī, le seul personnage pouvant répondre à cette identification est celui qui apparaît dans les chroniques, avec quelques variantes dans les nisba-s : al-amīr Māzī al-Ẓāhirī Barqūq ${ }^{76}$. Il est vraisemblable que cet émir du sultan Barqūq soit entré, à la mort de celui-ci, dans la clientèle de son fils Ibrāhīm (mort en 808/1413-1414) ${ }^{77}$ dont il aurait pris et conservé la

69. Al-SAHĀWī, Daw', I, p. 77.

70. Comme la Mosquée Riḡāl al-zawāyā au Mīdān qui était à l'origine une zāwiya fondée par un membre de la famille al-Mawșilī. Voir ṬAas 1975, p. 220-221 ; MARINo 1997, p. 77-78.

71. C'est-à-dire un descendant de la famille du prophète Muhammad, de la branche d'al-Ḥusayn b. 'Alīb. Abī Ṭālib.

72. AL-SAHĀWī, Daw', I, p. 77.

73. Communication de M. Ġazūla.

74. Wulzinger \& Watzinger 1924, p. 102, D. 18. 1 ; ṬAlAs 1975, p. 250, nº 261 ; 'UlāBī 1989, p. 362 ; Atassĩ \& Langhade 1994, p. 76, nº780 ; Roujon \& VILAN, 1997, p. 65, n²1; ŠIHĀBī 1999, I, p. 131.

75. ÖZKAn 2005, p. 108-109, n² 14. L'éditeur a lu Ġāzì à la place de Māzì.

76. Ce qui signifie que son maître est le sultan al-Ẓāhir Barqūq ( 784-791/1382-1389-792-801/1389-1399). SUBLET 1991, p. 30 ; B̈̄̄̌š 1987, p. 105-106.

77. IBn TAǴRİ BiRdī, Manhal, III, p. 327, nº 4 . 
nisba jusqu'à la construction de cette mosquée. Le fondateur fut émir à Damas ${ }^{78}$ avant d'occuper la fonction de gouverneur de Karak en 843/1439-1440 ${ }^{79}$. Il revint habiter Damas après avoir quitté toutes ses fonctions en 856/1452-1453 ${ }^{80}$. Cet émir vivait à Damas au moment où l'acte de waqf a été dressé. Il mourut en dū 1-hị̆ğa 864/septembre-octobre $1460{ }^{81}$. La date approximative de la construction de la mosquée se situe donc dans les années 1450.

Le plan rectangulaire actuel de l'édifice ne permet pas de retrouver les traces du mausolée (fig. 13). En effet, aucun vestige ne remonte au-delà de l'époque ottomane. La mosquée a été restaurée dans les premières décennies du $x^{e}{ }^{e}$ siècle ${ }^{82}$ et le minaret de pierres blanches a été érigé dans la seconde moitié du xxe siècle ${ }^{83}$ (fig. 11).

\section{Conclusion}

Ces identifications permettent de tirer quelques renseignements sur les constructions monumentales et le processus d'urbanisation du Mīdān à l'époque mamelouke. Il apparaît clairement que les militaires, ce que furent trois de nos quatre fondateurs, jouèrent un rôle majeur dans le développement du quartier et le structurèrent autour de monuments, en contribuant aussi à l'islamisation du paysage le long de la « voie sacrée » qu'était la route du pèlerinage. Ces hommes apparaissent alors comme de véritables évergètes qui, non seulement contribuent à l'édification de nouveaux monuments, mais aussi à la restauration d'édifices plus anciens en plaidant, par exemple en 730/1329 auprès du sultan, en faveur de la restauration du musallā des deux fêtes ${ }^{84}$. Au-delà de ces constructions, ils assurent le développement du quartier en s'y installant et en le peuplant de tout un monde d'hommes de religion, d'intendants et de serviteurs dont les salaires et l'entretien sont assurés par la constitution d'actes de waqf attachés à ces nouvelles constructions.

78. On ne connaît pas la fonction qu'il occupa.

79. Al-MaQRīīi, Sulūk, IV, p. 1173, 1201.

80. Ibn TAĠRī Birdī, Nuğūm, XV, p. 44.

81. IBN IYĀs, Badā' $i$ ' II, p. 363.

82. Selon Sarab Atassi, dans les années 1930, mais la date figurant sur une inscription au-dessus du mihrāb est 1339/1920-1921. Voir AtAssi \& LANGHADE 1994, p. 76, nº 780.

83. Țalas nous parle d'un minaret construit en basalte noir. Voir ȚALAS 1975, p. 250.

84. AL-ĞAZARī, Hawādiț, II, p. 389. 


\section{Bibliographie}

\section{Sources}

Aвū ŠĀmA, Dַayl 'alā al-Rawḍatayn, éd. M. al-Kawțarī, M. al-Ḥusaynī, Damas, Maktab našr al-țaqāfat aldīniyya, 1947.

'Aynī (AL-), 'Iqd al-ğumān fĩ Tārīh ahl al-zamān, éd. Muhammad Muhammad Amīn, Le Caire, Dār al-kutub, 5 vol., 1987-2009.

BiRzĀLì (AL-), al-Muqtafì 'alā Kitāb al-Rawḍatayn al-ma'rūf bi-Tārīh al-Birzālī, éd. 'Umar 'Abd al-Salām alTadmurī, al-maktabat al-'așriyya, Șaydā-Beyrouth, 4 vols., 2006.

ĞAZARĨ (AL-), Hawādiț al-zamān wa anbā'ih, éd. 'U. al-Tadmurī, Beyrouth, al-Maktaba al-'așrīyya, 1998.

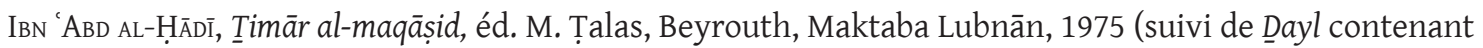
un inventaire des mosquées de Damas en l'année 1942 par Țalas lui-même).

IBN 'AsākiR, Tārīh Dimašq, éd. 'Umar al-'Amrāwī, Damas, Dār al-Fikr, 1995-2001.

Iвn 'AsĀkir, Tārihh Dimašq, éd . Ș. al-Munağğid, Damas, 1951 (pour la carte accompagnant cette édition).

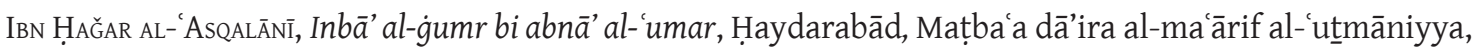
1970.

Iвn HुALLIK̄̄n, Wafayāt al-a'yān, éd. I. 'Abbās, Beyrouth, Dār al-țaqāfa, s.d.

IBN IYĀs, Badā’i al-zuhūr, éd. M. Mușțafā, Le Caire, al-Hay'a al-mișriyya al-‘̄mma li-l-kitāb, 1961-1986.

IвN KAṬT̄R, al-Bidāya wa al-nihāya, éd. 'Abd Allah al-Turk, Le Caire, Dār Hagar, 1998.

IвN QĀ̄ī Š UнBBA, Tārīh Ibn Qāḍ̄ Šuhba, éd. 'A. Darwīš, Damas, Institut français d'études arabes, 1974-1997.

IBN AL-QALĀNISĪ, Dַayl Tārīh Dimašq, éd. H. F. Amedroz, Beyrouth, Mațba'a al-abā' al-yasūīyyn, 1908.

IBN ŠADDĀD, al-A lāq al-hațīira, éd. S. al-Dahhān, Damas, Institut français d'études arabes, 1956.

IBN ȘASTRĀ, al-Durrat al-mudị̄a fĩ al-Dawlat al-zāhiriyya, éd. W. M. Brinner, Los Angeles, Berkeley, University of California Press, 1963.

IBN TAǴRī BiRDī, al-Manhal al-șâfĭ, éd. M. Amīn, Le Caire, al-Hay'at al-mișriyyat al-āmma li-l-kitāb, 19841994.

IBN TAĠRī BIRDĪ, al-Nuğūm al-zāhira, Le Caire, Wizārat al-țaqāfa al-mișriyya, 1933-1972.

IBN ȚAWQ, al-Ta'līq, éd. Ğ. al-Muhāğir, Damas, Institut français d'études arabes, 2000-2006.

IвN ṬūtūN, Mufākahāt al-hnillān, éd. M. Muṣtafā, Le Caire, Dār iḥyā’ al-turāt al-'arabī, 1962.

IBN Ṭūıūn, I'lām al-warā, éd. 'A. Dahmān, Damas, Dār al-fikr, 1984.

IBN ṬūLūN, al-Qalā’id al-ğawhariyya fì tārīh al-Ṣalihịyya, éd. 'A. Dahmān, Damas, Mağma' al-lug̉a al-'arabiyya, 1980.

Iвn WĀṣıL, Mufarriğ al-kurūb fī aḩbār banī Ayyūb, éd. J. D. al-Šayyāl, Le Caire, Dār al-Qalam, 1953-1977.

'Llmawī (AL-), Muhtașar tanbih al-țālib wa iršād al-dāris, éd. Ṣ. D. al-Munağğid, Damas, Mudīriyya al-atāār al‘āmma al-qadìma, 1947.

MaqRīzī (AL-), Kitāb al-Sulūk li-má rifa duwal al-muluk, éd. M. Ziyāda \& S. 'Āšūūr, Le Caire, 1970-1973.

Nu AYMī (AL-), al-Dāris fì Tārīh al-madāris, éd. Ǧ. al-Ḥasanī, Damas, Maktabat al-țaqāfa al-dīniyya, 1973.

QALQAŠANDī (AL-), Șubḥ al-a ǎša fì șinā'at al-inšă’’ le Caire, Wizāra al-țaqāfa al-mișriyya, 1913-1919. 
SAHĀWī (al-), al-Ḍaw' al-lāmi', Beyrouth, Dār maktabat al-Ḥayāt, s. d.

SuBKī (AL-), Fatāwā al-Subkī, Beyrouth, Dār al-Ma'rifa. s. d.

YĀQūT AL-ḤAmawī, Mu'ğam al-buldān, Beyrouth, Dār Șādir, 1984.

\section{Études}

ANoNYME, « Iktišāf madfan rūmānī 'atarāi fī waǧibat mašfā al-Muğahid bi-Dimašq ». URL : http://www. discover-syria.com/news/4637. Consulté le 10 juin 2011.

ATASSI, Sarab, LANGHADE, Jacques, 1994 : Damas extra-muros, Midan al-Sultanî, présentation et analyse des édifices répertoriés, circonscription 36 section 1-3, Damas, Institut français d'études arabes.

BĀšĀ, Ḥasan (AL-), 1987 : Al-alqāb al-islāmiyya, Beyrouth, Dār al-nahḍa al-'arabiyya.

Cartes Damas: 1/10000, «dressé, dessiné et publié par le service géographique des FFLL, d'après réduction des plans cadastraux, mai $1942 \%$.

Dayoub, Bassam, 2010 : « Mayādīn Dimašq », Apollodore 13, p. 132.

DEGEORGE, Gérard, 1997 : Damas, des origines aux Mamluks, Paris, Harmattan.

Dodinet, Marianne, Leblanc, Jacques, Vallat, Jean-Pierre, Villeneuve, François, 1990 : « Le paysage antique en Syrie : l'exemple de Damas », Syria 67/2, p. 339-367.

Dussaud, René, 1927 : Topographie historique de la Syrie antique et médiévale, Paris, Librairie Orientaliste Paul Geuthner.

ḤAmūDA, Muḥammad, 2010 : « Nasīb Șalībī, 'Ālim al-ațār al-lad̄i iftaqdnāh ». URL : http://www.dgam.gov. sy/?d=227\&id=833. Consulté 10 juin 2011.

HuURAYsāT, Muhammad, 1992: "al-Tawasu' al-'umrāni li-madinat Dimašq fi al-'ahd al-fāțimī», in Muḥammad BАН̆̄T (dir) : Mū'tamar Bilād al-Šām fï al-'așr al-'abbāsī, Mū'tamar al-ḩāmis, 'Ammān, p. 390428.

MAYER, Leo Ary, 1933 : Saracenic Heraldry, New York, Oxford University Press.

Marino, Brigitte, 1997 : Le faubourg du Midan à l'époque ottomane : espace urbain, société et habitat, 1742-1830, Damas, Institut français d'études arabes.

MeINECKE, Michael, 1992 : Die Mamlukische Architektur in Ägypten und Syrien (648/1250 bis 923/1517), Glückstadt, Verlag J. Augustin GMPH.

MunaǦĞID, Șalāḥ al-Dīn (AL-), 1949 : Hițaț Dimašq al-qadīma, Beyrouth, al-Maṭba'a al-kātēulikiyya.

ORY, Solange \& MoAz, Khaled, 1977 : Inscriptions arabes de Damas : Les stèles funéraires, I. cimetière d'al Bab alSaghir, Damas, Institut français de Damas.

ÖZKAN, Aydin, 2005 : Misir Vakiflari: Osmanli Devri Ve öncesi, Istanbul : İslam Tarih, Sanat ve Kültürünü Araştırma Vakfi.

PAscual, Jean-Paul, 1983 : Damas à la fin du Xvi siècle d'après trois actes de waqf ottomans, Damas, Institut français de Damas.

RīHāwī, 'Abd al-Qādir (AL-), 1979 : al-'Amāra al-'arabiyya al-islamiyya fì Sūriyya, Damas, Wizārat al-țaqāfa.

Roujon, Yves, Vilan, Luc, 1997 : Le Midan, actualité d'un faubourg de Damas, Damas, Institut français d'études arabes.

SAliBY, Nessib, 1982: "Un hypogée découvert dans un faubourg de Damas ", in Archéologie au Levant: recueil à la mémoire de Roger Saidah, Lyon (Collection de la Maison de l'Orient méditerranéen 12, série archéologique 9), p. 305-309.

SAUVAGET, Jean, 1932 : Les monuments historiques de Damas, Beyrouth, Imprimerie catholique. 
Sauvaget, Jean, Mantran, Robert, 1951: Règlements fiscaux ottomans : les provinces syriennes, Beyrouth, Imprimerie catholique.

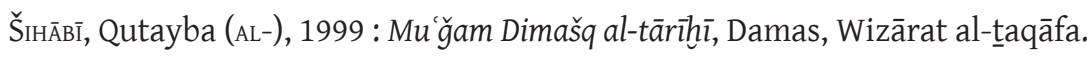

Sublet, Jacqueline, 1991: Le voile du nom. Essai sur le nom propre arabe, Paris, Presses universitaires de France.

WATZInGER, Carl \& Wulzinger Karl, 1924: Damaskus die Islamische Stadt, Berlin and Leipzig, Walter de Gruyter $\&$ co. 
Liste des monuments bordant la rue principale du Mīdān

\begin{tabular}{|c|c|c|c|}
\hline Nom & Localisation & Epoque & Remarques \\
\hline $\begin{array}{l}\text { Mosquée Ğūbān } \\
\text { (Mausolée de l'émir Alțunbugiāa) }\end{array}$ & B.1.1 & Mamelouke & Disparue \\
\hline Mausolée de l'émir 'Arāq al-Silaḥdār & B.2.1 & Mamelouke & Fermé \\
\hline Maqām Sīdī Ṣuhayb & B.2.2 & Ayyoubide & Restauré en 606/1209-1210 \\
\hline $\begin{array}{l}\text { Maqām al-Ḥarmal̄̄ } \\
\text { (Mausolée al-Qurāǧiyya) }\end{array}$ & B.2.3 & Mamelouke & Actuellement un restaurant \\
\hline Mausolée al-Zūwayzāniyya & B.2.4 & Ayyoubide & $\begin{array}{l}\text { Actuellement le mausolée de la } \\
\text { famille Habb al-Rummān }\end{array}$ \\
\hline Mosquée Fūlūs & B.2.5 & Fatimide & $\begin{array}{l}\text { Actuellement la Zāwiya al- } \\
\text { Rifā'iyya }\end{array}$ \\
\hline Mosquée al-Mūṣallī & B.2.6 & Ottomane & \\
\hline Mausolée al-Qurašĩ & B.3.1 & Ottomane & \\
\hline Mausolée Abū l-Nūr & B.3.2 & Ottomane & \\
\hline Mosquée al-Rifā‘̄i & B.3.3 & Mamelouke & $\begin{array}{l}\text { Reconstruite complètement à } \\
\text { l'époque ottomane }\end{array}$ \\
\hline Mosquée al-Ğunayd & B.3.4 & Mamelouke & $\begin{array}{l}\text { Reconstruite dans les années } \\
\text { trente du xx siècle. }\end{array}$ \\
\hline Mosquée al-Qurašī & B.3.5 & Ottomane & \\
\hline Mosquée Manğak & C.4.1 & Mamelouke & $\begin{array}{l}\text { Il ne reste de l'ancien monument } \\
\text { que le minaret et quelques assises } \\
\text { de la façade ouest }\end{array}$ \\
\hline Mosquée Abū l-Ṣafā & C.4.2 & Mamelouke & Pas de vestiges mamelouks \\
\hline Mosquée al-Ḥallāğ & C.4.3 & Mamelouke & Disparue \\
\hline Mausolée de Sulaymān al-Ğāmūs & C.5.1 & Mamelouke & \\
\hline Mausolée al-Taynabiyya & C.5.2 & Mamelouke & \\
\hline Mosquée al-Ḩānqiyya & C.5.3 & Mamelouke & \\
\hline $\begin{array}{l}\text { Zāwiya al-Sa‘diyya } \\
\text { (Mausolée al-Ğakamiyya) }\end{array}$ & D.6.1 & Mamelouke & $\begin{array}{l}\text { Reconstruite complètement à } \\
\text { l'époque ottomane }\end{array}$ \\
\hline Mosquée d'al-Qunšliyya & D.7.1 & Mamelouke & \\
\hline Zāwiya al-Rašĩdiyya & D.7.2 & Mamelouke & \\
\hline Mosquée al-Karīmī (al-Daqāq) & D.7.3 & Mamelouke & \\
\hline Mosquée Māzī & E.8.1 & Mamelouke & Reconstruite à l'époque ottomane \\
\hline
\end{tabular}




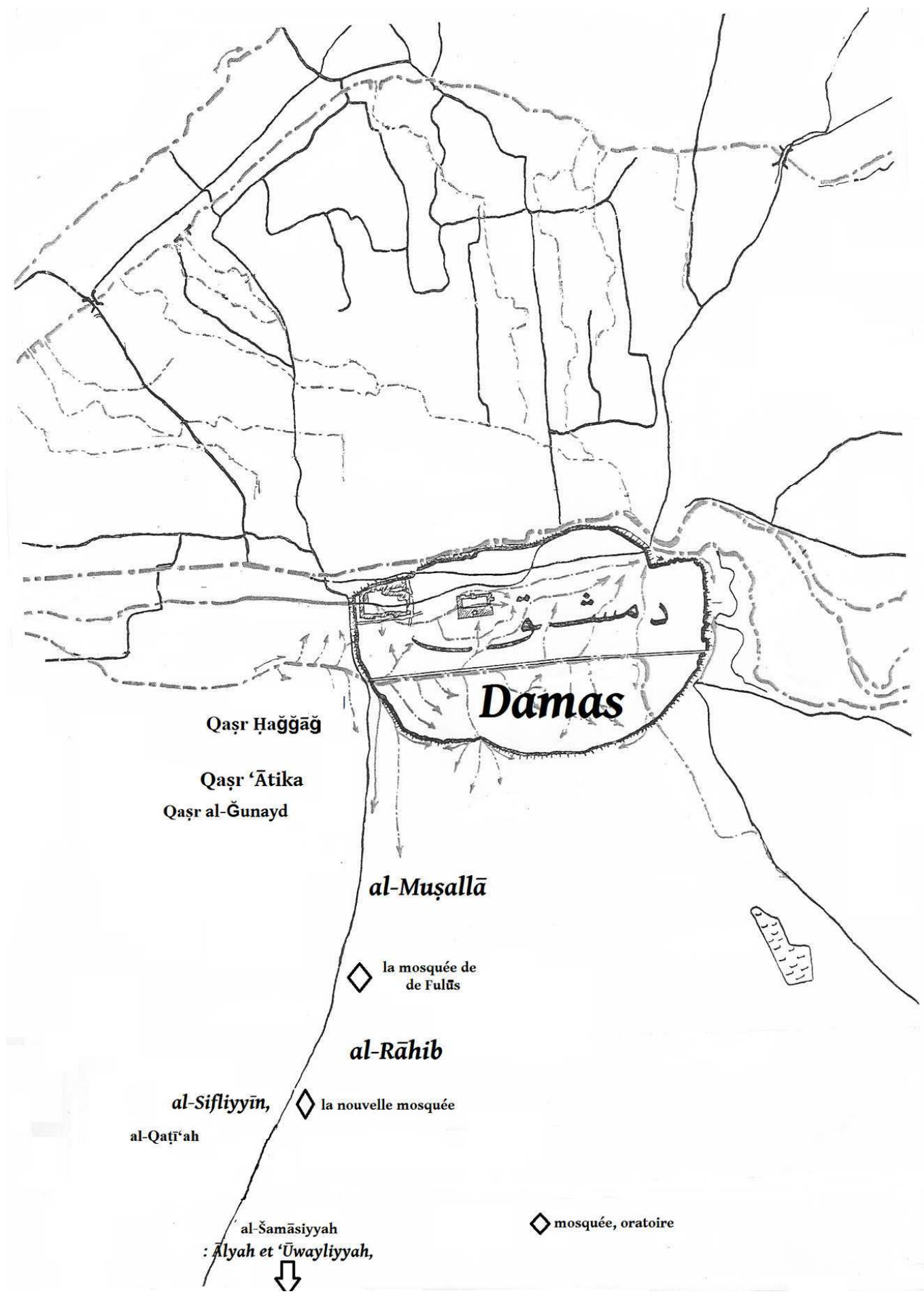

Carte 1 - Les villages au sud de Damas (Dayoub d'après MunaĞĞID 1951). 


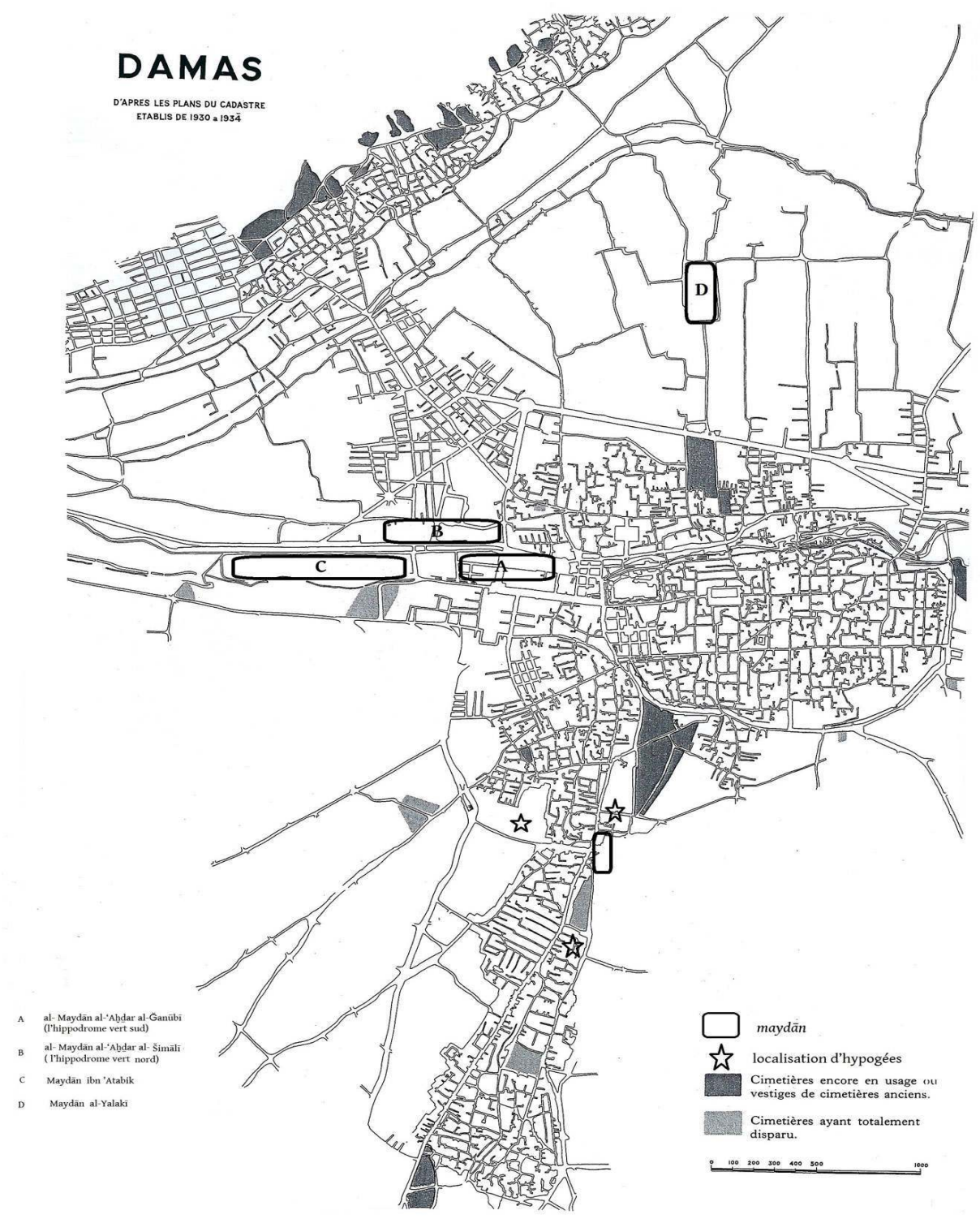

Carte 2 - Damas : les maydān-s et localisation d'Hypogées au sud (Dayoub d'après ORY \& MOAz 1977). 
D

C

B

A

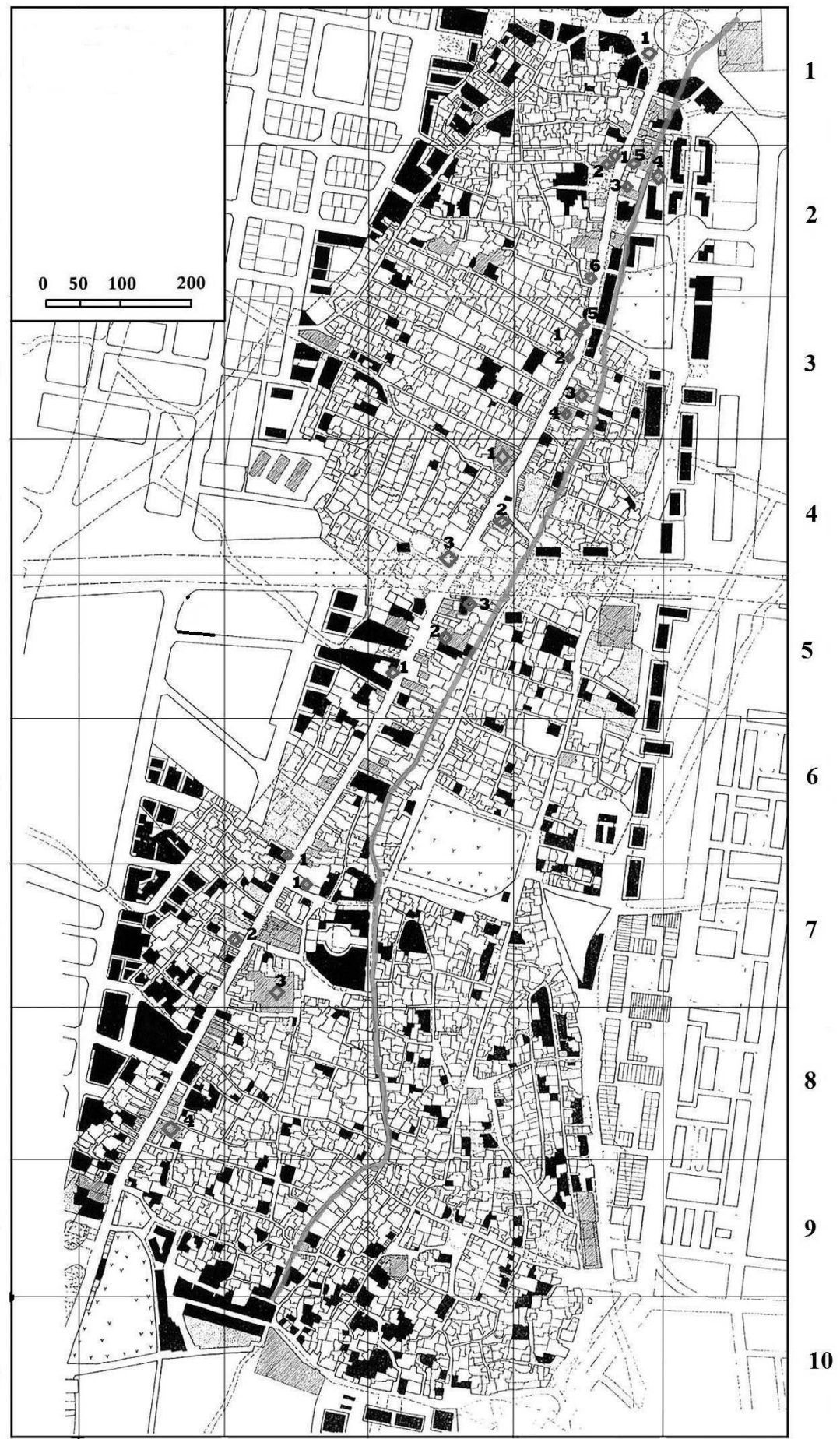

Carte 3 - Carte du Mīdān d'après Roujon \& VILAN 1997. 


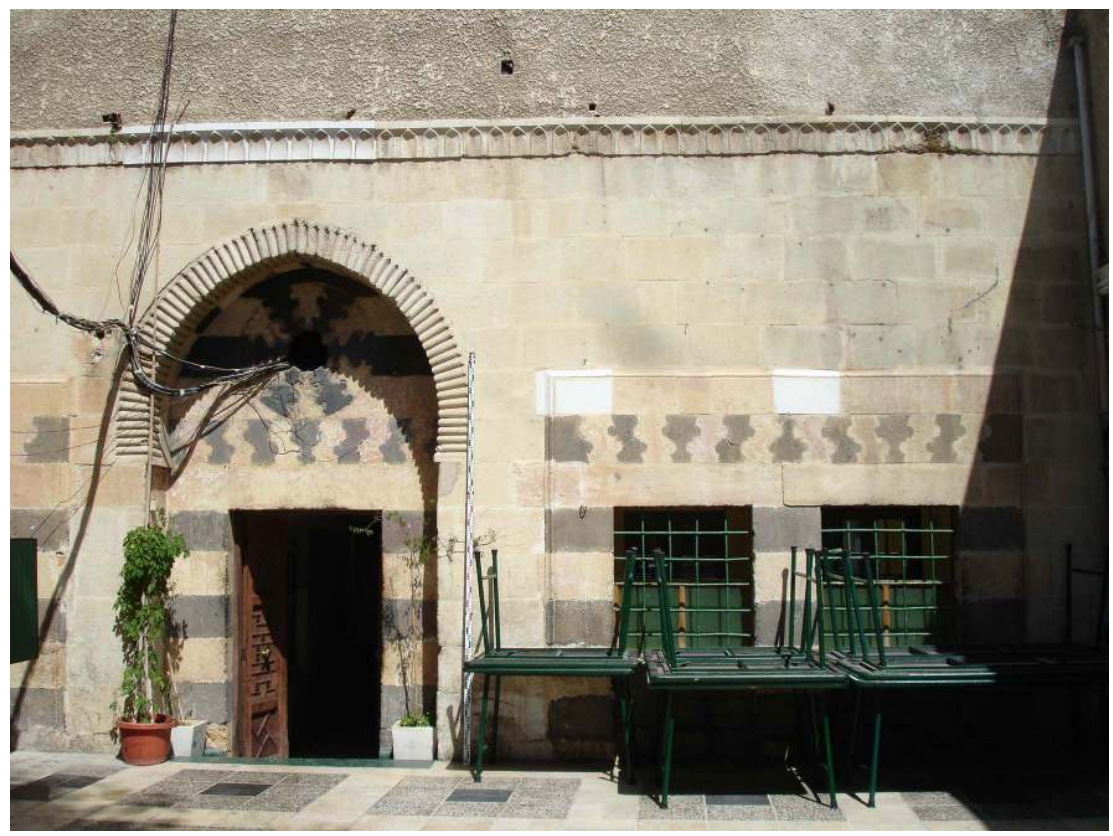

Fig. 1 - Maqām al-Ḥarmalī (le Mausolée al-Qurāğiyya). La façade. Partie gauche (cl. Dayoub, 2009).

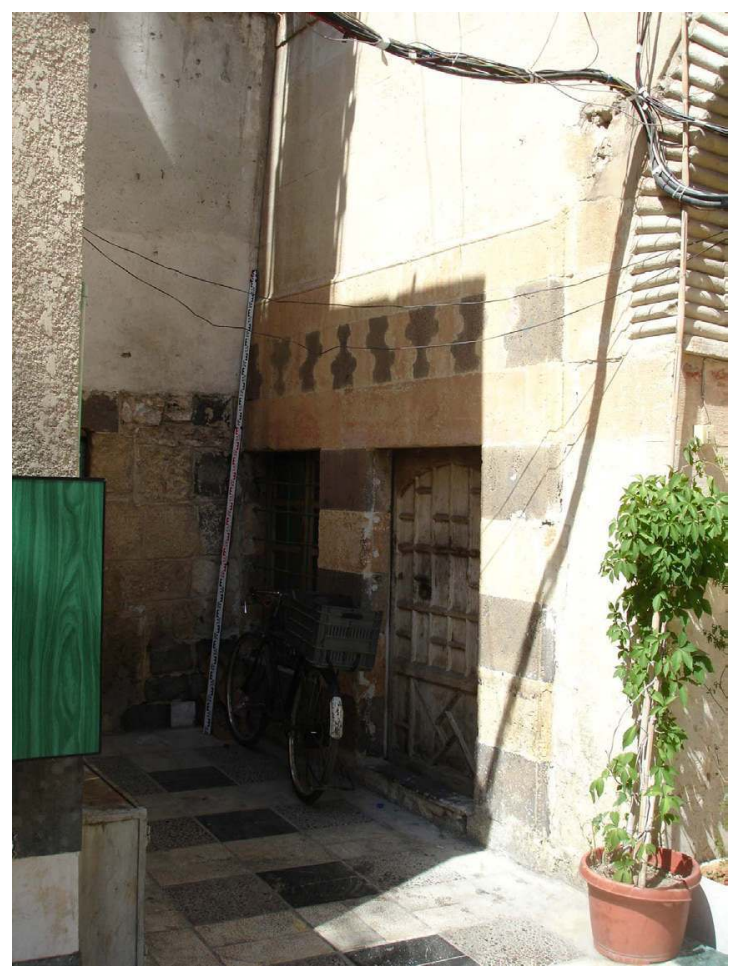

Fig. 2 - Maqām al-Ḥarmalī (le Mausolée al-Qurāǧiyya). Partie droite de la façade (cl. Dayoub, 2009). 


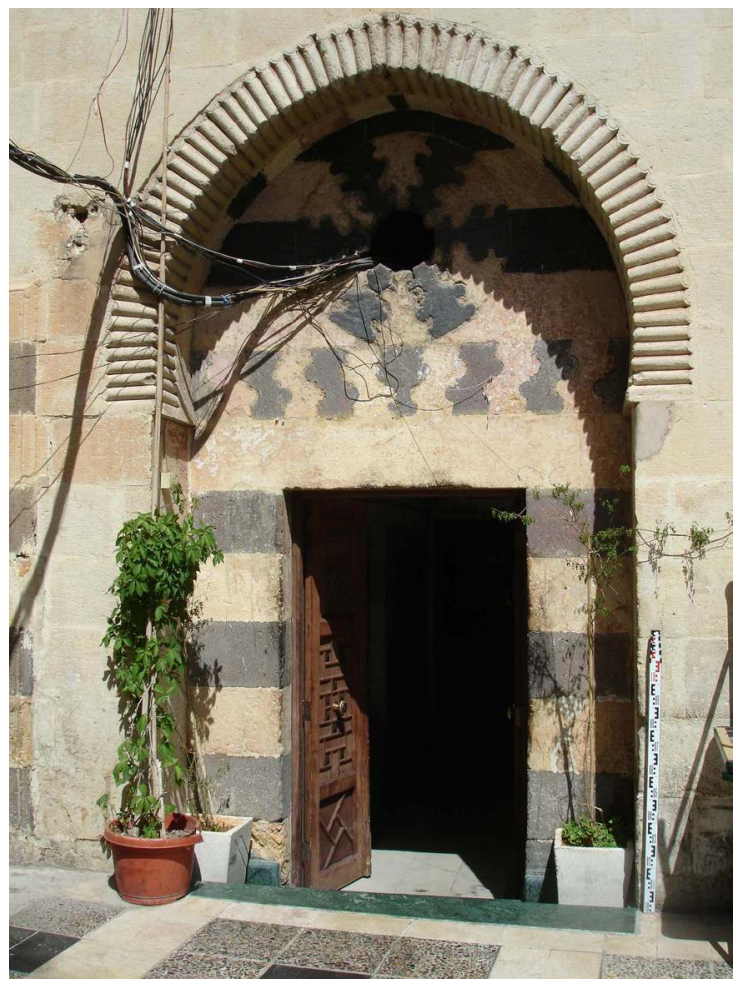

Fig. 3 - Maqām al-Ḥarmalī (le Mausolée al-Qurāğiyya). Portail (cl. Dayoub, 2009).

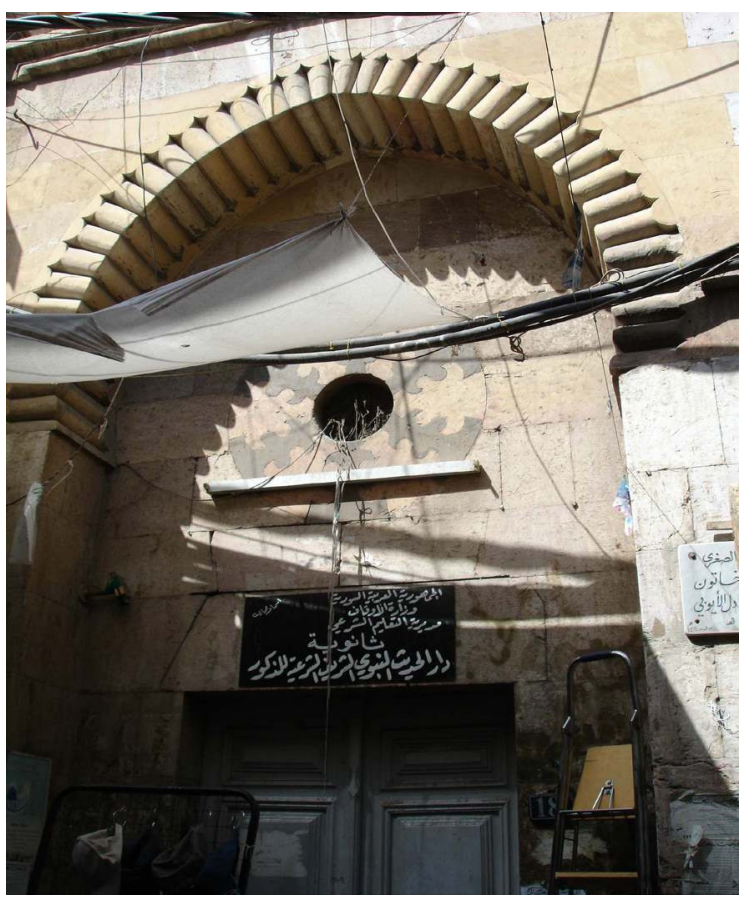

Fig. 4 - Madrasa al-'Ādiliyya al-ṣug̉rā. Portail (cl. Dayoub, 2009). 


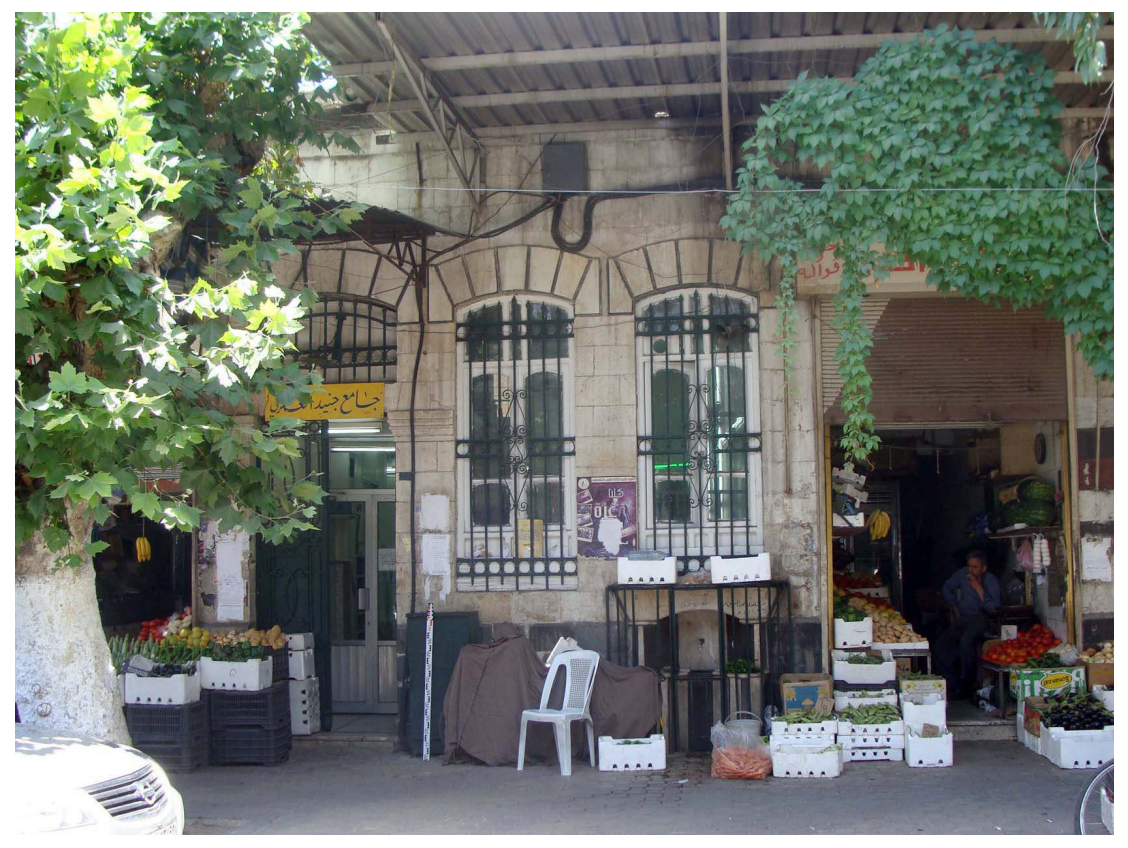

Fig. 5 - Mosquée d’al-Ğunayd al-'Askarī. Façade (cl. Dayoub, 2009).

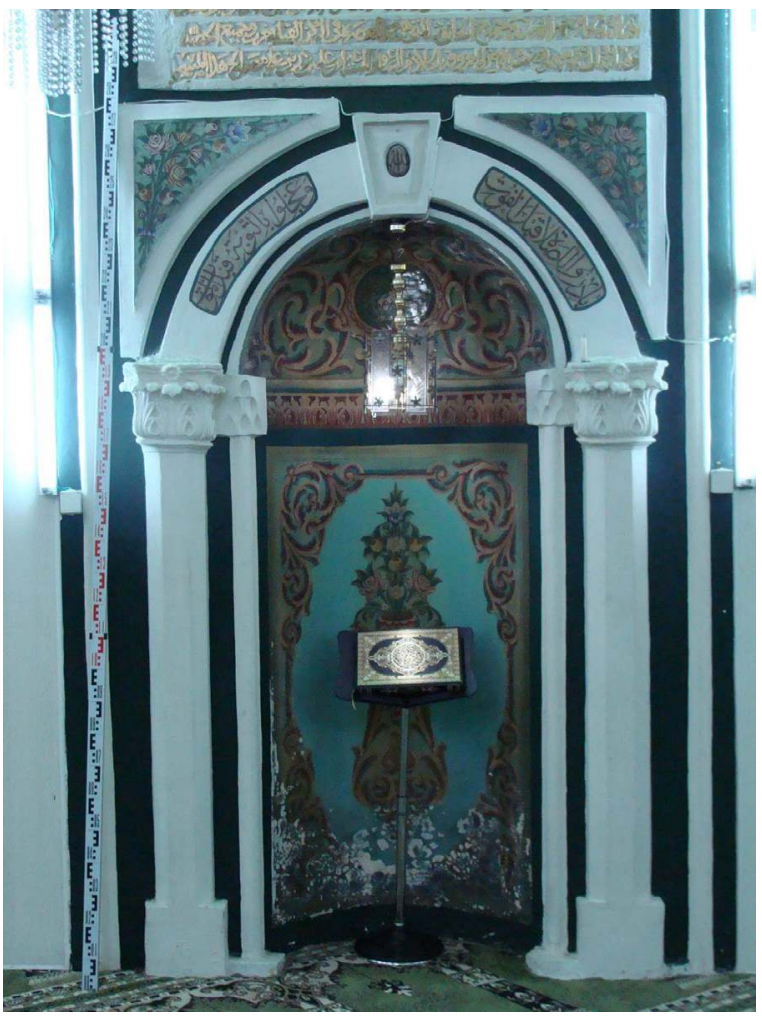

Fig. 6 - Mosquée d’al-Ğunayd al-'Askarī. Miḥrāb (cl. Dayoub, 2009). 


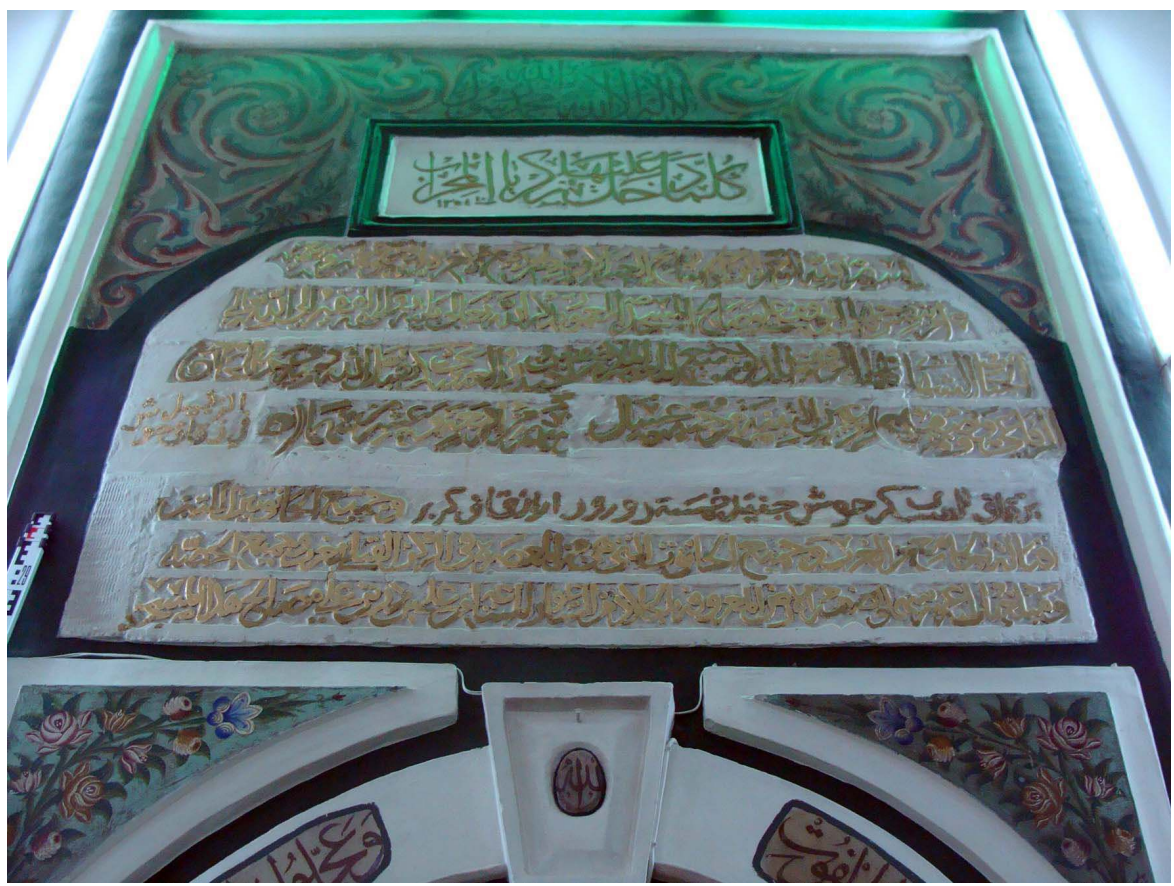

Fig. 7 - Mosquée d'al-Ğunayd al-'Askarī. Inscription au-dessus du mihrāb (cl. Dayoub, 2009).

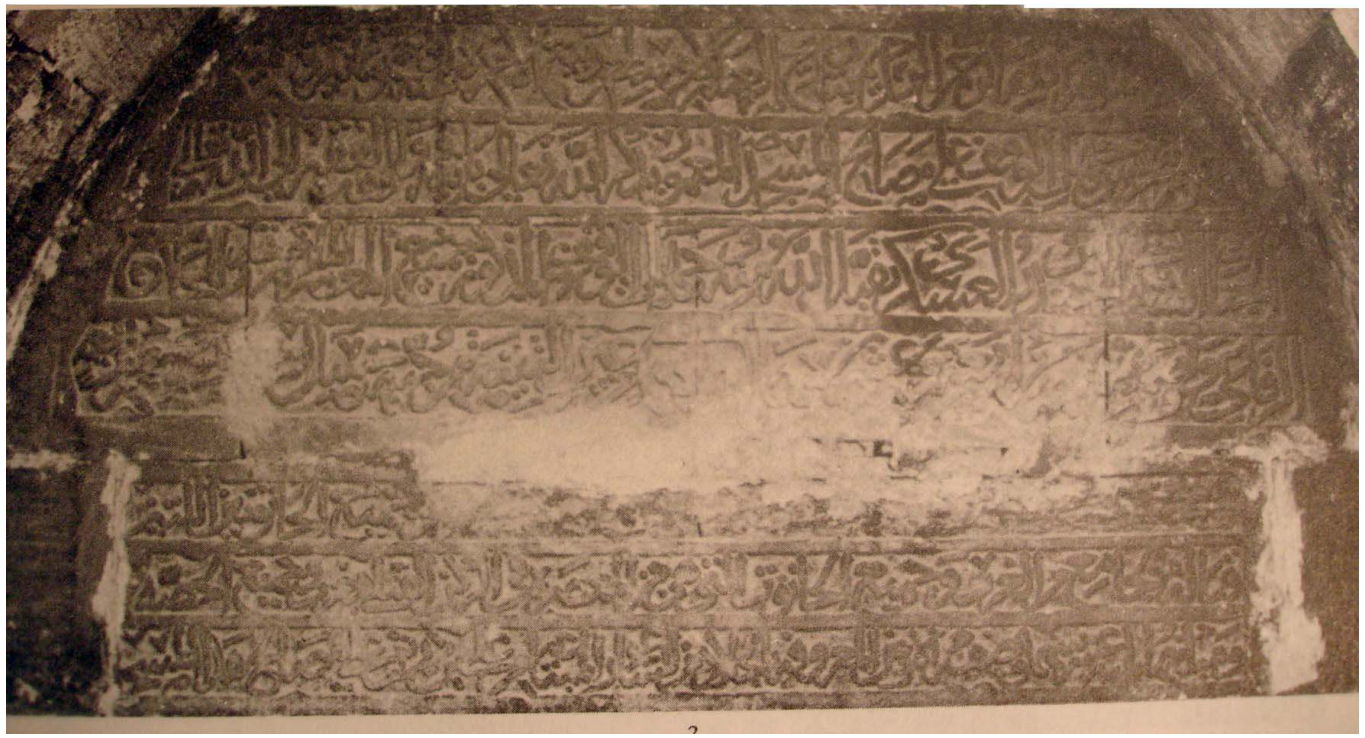

Fig. 8 - Mosquée d'al-Ğunayd al-'Askarī. Inscription au-dessus du mihrāb avant les modifications (d'après MAYER 1999, pl. XIX.2). 


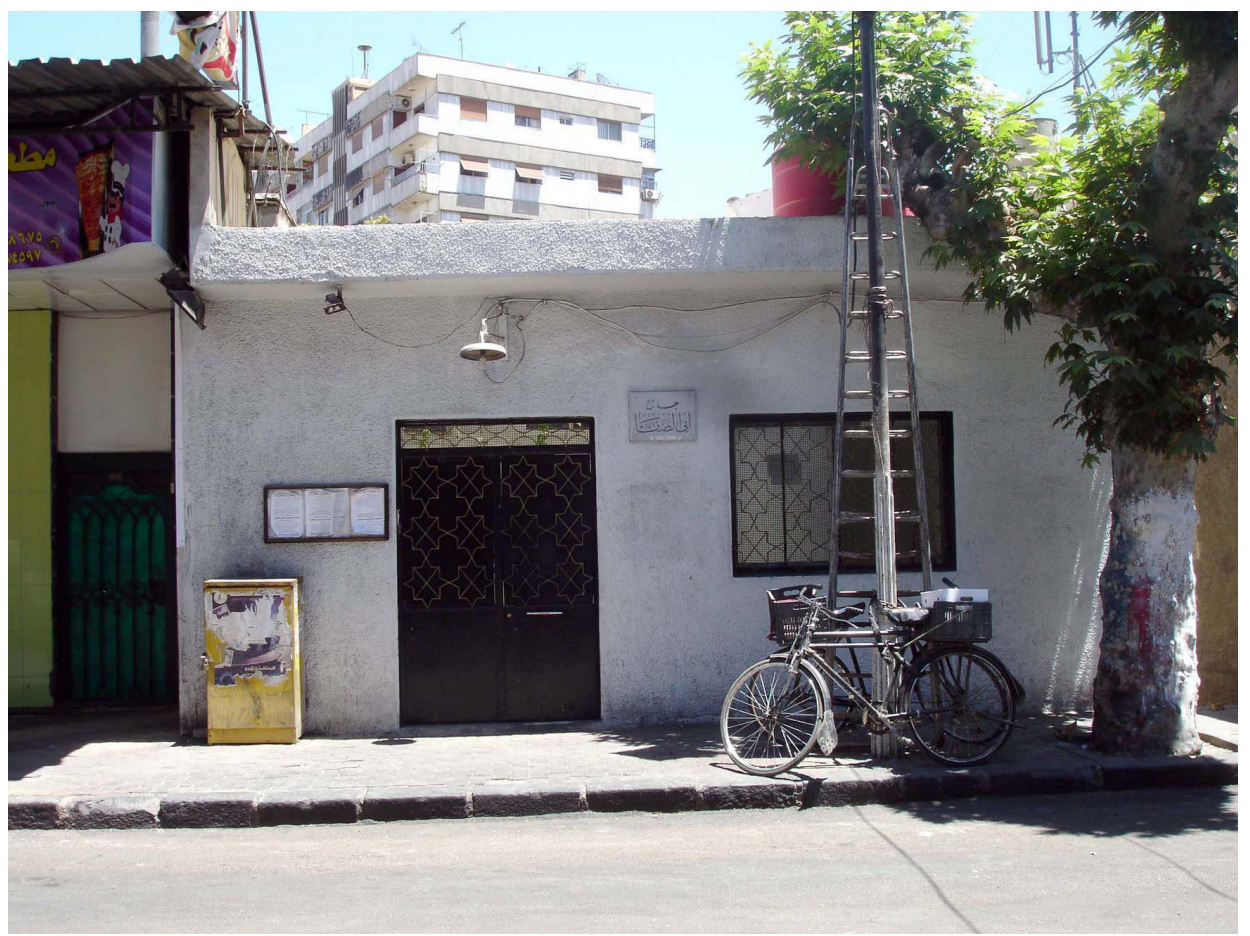

Fig. 9 - Mosquée Abū l-Șafā. Façade sur rue (cl. Dayoub, 2009).

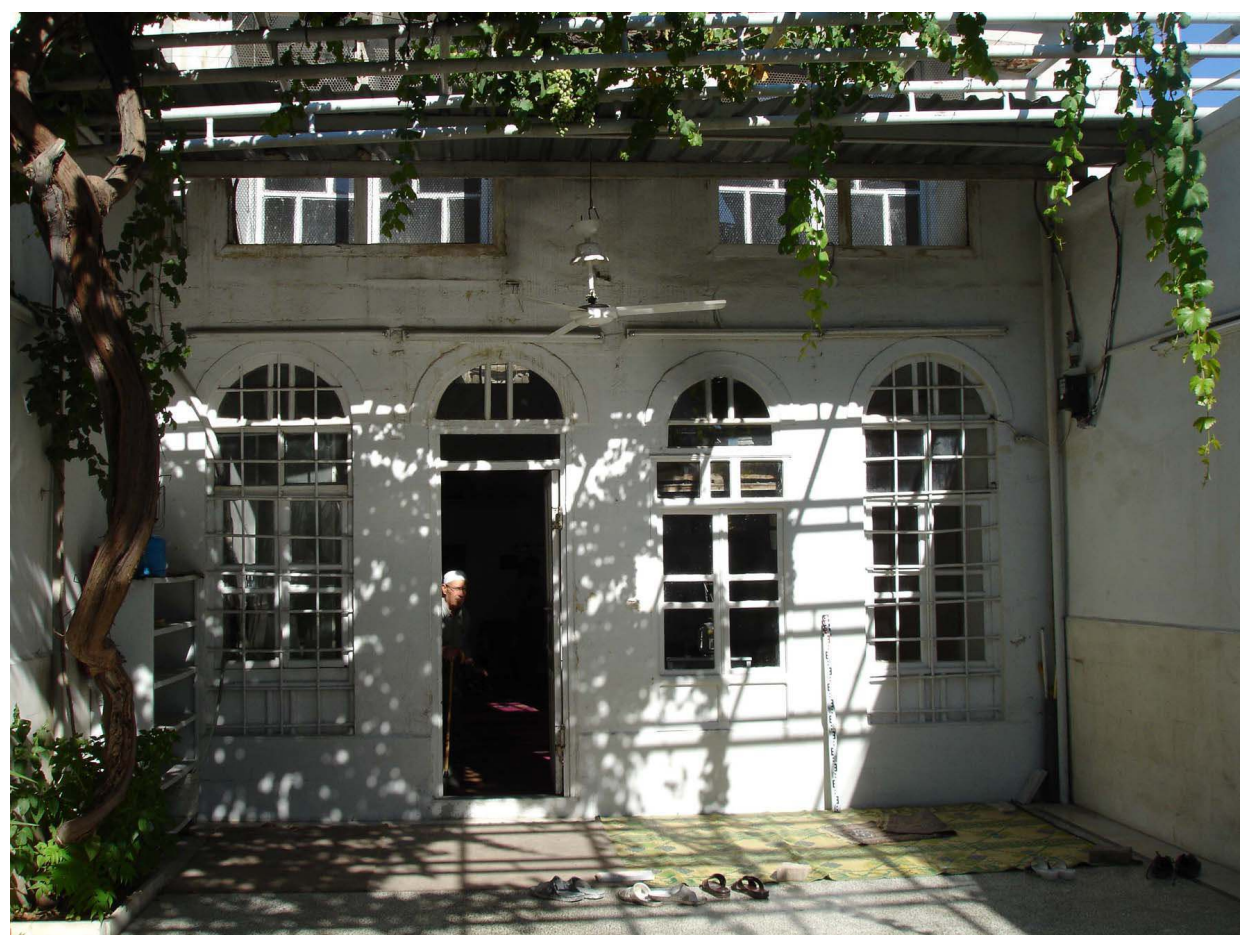

Fig. 10 - Mosquée Abū l-Ṣafā. Façade intérieure et cour (cl. Dayoub, 2009). 


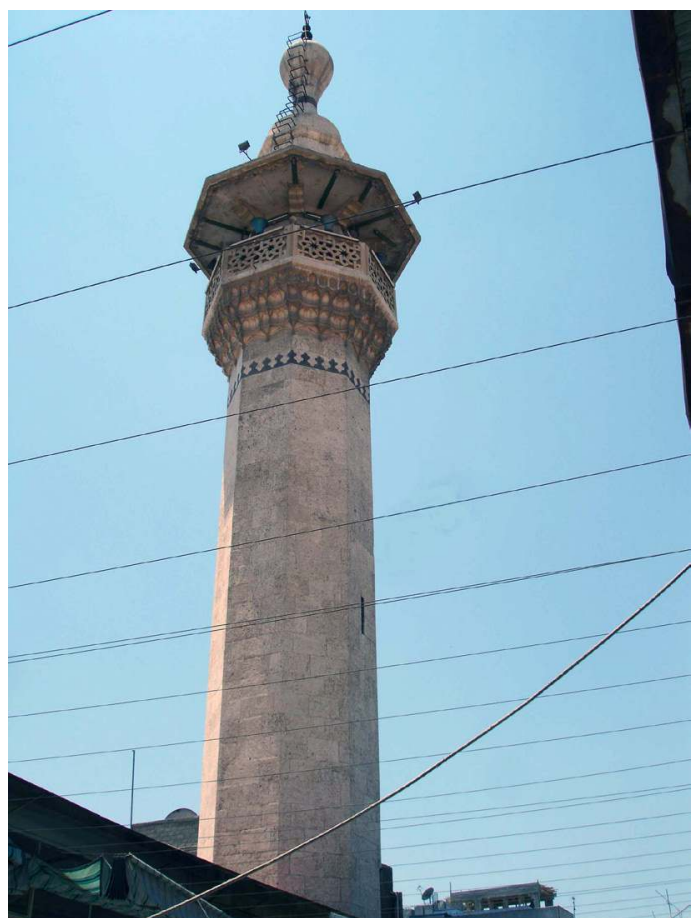

Fig. 11 - Mosquée de Māzī. Minaret (cl. Dayoub, 2009).

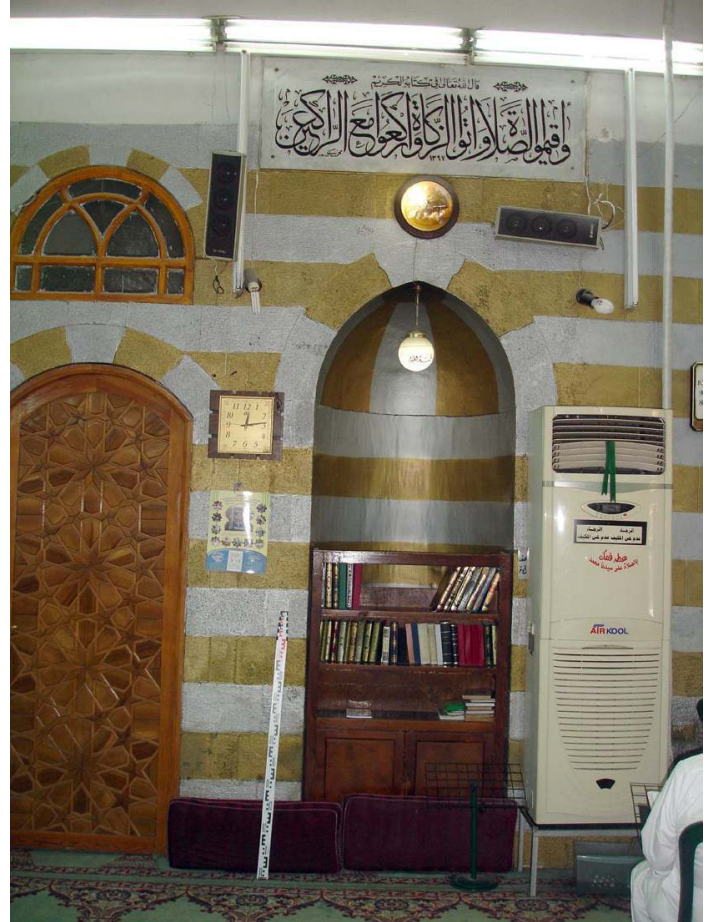

Fig. 12 - Mosquée de Māzī. Miḥrāb (cl. Dayoub, 2009). 


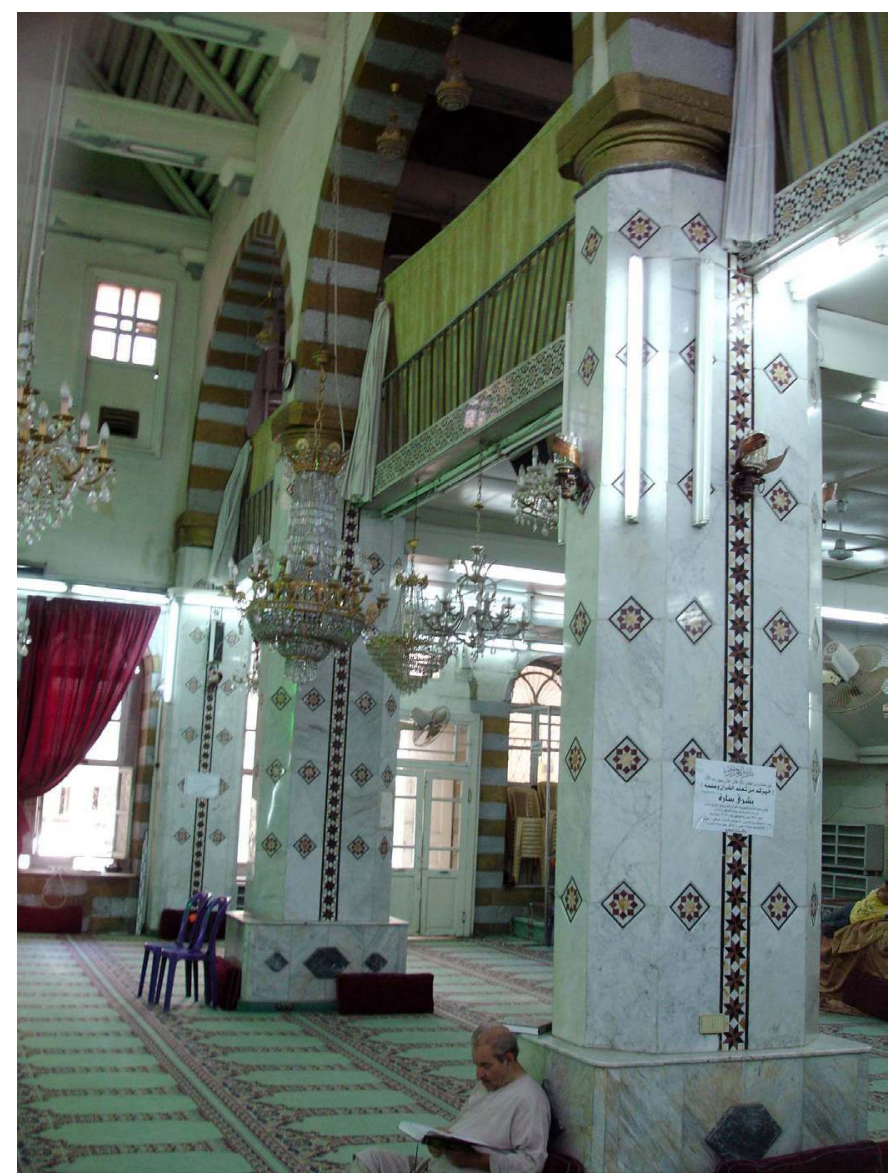

Fig. 13 - Mosquée de Māẓ̄. Intérieur de la salle de prière (cl. Dayoub, 2009). 